\title{
The effect of positive psychotherapy in test anxiety among Zahedan students with hemophilia
}

\author{
Mahbobe Ghavidel Heydari, ${ }^{1}$ Mahmoud Shirazi, ${ }^{2}$ Gholam Reza Sanagouyemoharer ${ }^{1}$ \\ ${ }^{1}$ Department of Psychology, Zahedan Branch, Islamic Azad University, Zahedan; ${ }^{2}$ Department of Psychology, Faculty of Educational \\ Sciences and Psychology, University of Sistan and Baluchestan, Zahedan, Iran
}

\begin{abstract}
Hemophilia is a chronic disease which due to several reasons, including frequent absences from school and reduced motivation, leads to the incident of test anxiety among patients. This study was conducted with the aim of evaluating the effectiveness of positive psychotherapy in test anxiety among students with hemophilia. The current study followed a pretest, posttest, and two-month followup quasi-experimental design with an experimental group and a control group. This study had a statistical population including all senior elementary and junior high school students with hemophilia who had medical records in Zahedan Hemophilia Society. After screening them, 60 students were selected and randomly assigned to two 30-person groups of experimental and control. Since some patients refused to continue taking part in this study, the sample decreased to 57 people. Measurement tool used in this study was Sarason Test Anxiety Scale. Positive psychotherapy was held in 8 sessions (two 120-minute sessions per week) and a follow-up was conducted two months after completing the psychotherapy. Data were analyzed using a repeated measure analysis of variance. Results showed that positive psychotherapy significantly reduced test anxiety among the students with hemophilia. Moreover, the stability of the effects of this therapy in the follow-up was confirmed. The obtained results indicated that policymakers should pay a lot of attention to this new positive psychological training and its effects on reducing test anxiety.
\end{abstract}

Key words: Hemophilia; Positive psychotherapy; Students; Test anxiety.

Correspondence: Mahmoud Shirazi, Department of Psychology, Faculty of Educational Sciences and Psychology, University of Sistan and Baluchestan, Shariati Ave, Zahedan, Iran, Post code 9813685399.

Tel.: +98.9153404219

E-mail: mahmoud.shirazi96@gmail.com

Conflict of interest: the authors declare no potential conflict of interest.

Contributions: MGH carried out the experiment and wrote the manuscript with support from MS and GRS. MS was involved in planning and supervised the work. GRS contributed to the design and implementation of the research, to the analysis of the results and to the writing of the manuscript.

Acknowledgements: the authors would like to express their sincere appreciation to all the patients who participated in this study, Ms. Salmanian, the head of Zahedan Hemophilia Society and Dr. Homeira Mahmoudi Souran who helped them in carrying out this study.

Funding: none.

Received for publication: 15 February 2018.

Revision received: 27 March 2018.

Accepted for publication: 27 March 2018.

This work is licensed under a Creative Commons Attribution NonCommercial 4.0 License (CC BY-NC 4.0).

CCopyright M.G. Heydari et al., 2018

Licensee PAGEPress, Italy

Research in Psychotherapy:

Psychopathology, Process and Outcome 2018; 21:55-61

doi:10.4081/ripppo.2018.307

\section{Introduction}

Hemophilia is a chronic debilitating disease and a hereditary blood clotting disorder that is accompanied with multiple complications and can be diagnosed in the childhood by excessive surgical bleeding during a circumcision or any other surgeries (DeKoven et al., 2014; Iannazzo et al., 2017). Since patients with hemophilia require special home care and/or specific medical care (Iannazzo et al., 2017; Jafari, Mohtashami, Alaee Karahroudi, Mansouri, \& Rassouli, 2016) this disease significantly affects normal activities of these patients, including children and adolescents with hemophilia, and their caregivers (Rambod, Forsyth, Sharif, \& Khair, 2016; Sidonio, Holot, \& Cooper, 2017). Moreover, hemophilia leads to the incident of pharmaceutical symptoms, immobility, frequent absences from school and school dropout (Iannazzo et al., 2017; Sidonio et al., 2017), which can interfere with patients' happiness and well-being and affect their interactions with others (Iannazzo et al., 2017). Chronic pain creates numerous mental issues for patients with hemophilia, disrupts their social interactions, affects all aspects of their lives and ultimately, leads to social deprivation (Linton \& Shaw, 2011). These patients stay home and feel lonely and this feeling of loneliness creates anxiety, life hatred, and disappointment (Rambod et al., 2016). Frequent absences from school have a significantly negative effect on children's social and emotional development and can lead to academic failure and even school dropout (Vanneste, van de Loo, Feron, Rots-de Vries, \& van de 
Goor, 2016). On the other hand, children who undergo severe medical treatments and their lives are threatened by a disease experience high levels of anxiety and distress (Mento et al., 2015; Strauss, Last, Hersen, \& Kazdin, 1988). Test anxiety is a type of generalized anxiety disorders and defines as a series of physical, psychological and behavioral unwanted responses when somebody preparing for or taking a test (Shoshani, Mifano, \& Czamanski-Cohen, 2016; Zunhammer, Eichhammer, \& Busch, 2014). Several studies have confirmed that in childhood and adolescence anxiety is significantly associated with depression (Strauss et al., 1988). Moreover, given the age of puberty and its psychoemotional impacts on adolescents, patients with hemophilia are likely to go through very bad conditions in this period (Kendall, Hudson, Gosch, Flannery-Schroeder, \& Suveg, 2008; Wood et al., 2009). In addition, research revealed that general anxiety plays a key role in creating and developing severe test anxiety (Donovan \& Spence, 2000). Test anxiety is an unpleasant emotional response to an evaluation. This emotion is associated with stress, tension, and arousal of the automatic nervous system and plays an important role in creating psychological disruptions among students. All of these may lead to school dropout, threaten a person's mental and physical life (Kendall et al., 2008; Wood et al., 2009) and expose adolescent patients to a variety of mental and academic problems. Signs of test anxiety are alike symptoms of anxiety. As a person grows, his/her test anxiety increases. It seems that test anxiety forms and stabilizes at the age of 10 to 11 and continues until adulthood. Furthermore, according to results of previously carried out studies, the prevalence of test anxiety among student's ranges from $10 \%$ to $30 \%$ (Donovan \& Spence, 2000). Since student patients should deal with both educational and physical issues, a progression of the disease may interfere with their academic and social activities. Therefore, providing psychological support and protect mental health for children and adolescents with chronic diseases are important (Torres-Ortuño, Cid-Sabatel, Barbero, \& García-Dasí, 2017). Moreover, being positive lead to reducing test anxiety by different mechanism for example having positive approach to stressful events, optimize the immune systems functions and prevent dysregulation of immune responses (De Moor et al., 2006; Takahashi, Flanigan, McEwen, \& Russo, 2018) and therapeutic interventions can aid children and adolescents to deal with an acute disease more effectively, lead to significant reductions in general distress and signs of anxiety and improvement in these patients' quality of life (Shoshani et al., 2016). Given the age and characteristics of children and adolescents, a method that is considered among psychological therapies and can be applied to enhance mental health among these people is positive psychotherapy. Studies indicated that essential skills for promoting reality-based optimism and being positive, which immunize children and adolescents against mental issues, can be teach to them (Seligman \& Csikszentmihalyi, 2014; Seligman, Steen, Park, \& Peterson, 2005; Stewart, Watson, Clark, Ebmeier,
\& Deary, 2010). Positive psychotherapy refers to applying interventions through increasing positive emotions, raising the level of positive engagement in life and promoting life meaningfulness. Instead of focusing on the possibility of failure, positive people like to pay more attention to their competencies and what they have (Ji, Holmes, \& Blackwell, 2017; Seligman \& Csikszentmihalyi, 2014; Seligman et al., 2005). Hence, positive psychology can increase patients' resistance to various diseases (Khodabakhsh, Khosravi, \& Zarrinpour, 2015). Although several studies investigated the effectiveness of positive psychotherapy in reducing test anxiety (Bagana, Raciu, \& Lupu, 2011; Bolier et al., 2013) there are few attempts to manage psychological complications and psychological treatment even in hemophiliac adolescents (Caldwell, Leveque, \& Lane, 1974). To our knowledge, no studies were carried out to examine the effectiveness of positive psychotherapy in test anxiety among patients with hemophilia, especially in student patients. Therefore, evaluating the effectiveness of positive psychotherapy in test anxiety among students with hemophilia, based on the results, has significant importance to help authorities, especially authorities of the education system and medical policymakers to properly develop a plan with regard to special needs of these students. This study sought to answer the following question: Is positive psychotherapy effective in reducing test anxiety among students with hemophilia?

\section{Methods}

This clinical trial followed a pretest, posttest, and follow-up quasi-experimental design with an experimental group and a control group. Statistical population of this study consisted of all senior elementary school and junior high school students with hemophilia who had medical records in Zahedan Hemophilia Society. To determine the sample size required to carry out the current study, a table developed by Cohen (1986) was applied. Given the two groups (experimental and control), the following margin of error $(\alpha=0.05)$, the effect size of 0.50 and the test power of $0.97,30$ individuals were considered as the required sample (Sarmad, Bazargan, \& Hejazi, 2002). In this regard, among students with hemophilia referred to Zahedan Hemophilia Society, 60 students, whose scores on Test Anxiety Scale for children and Adolescents were higher than the mean cutoff point (13 and higher), were selected using a convenience sampling method and were randomly assigned to an experimental group (30 individuals) and a control group (30 people or a group of people on the treatment waiting list). Since a subject assigned to the experimental group refused to take part in the therapy sessions from the third session and due to lack of access to two of the subjects assigned to the control group, the sample of this study reduced to 57 individuals (Table 1 presents experimental and control groups statistics. Inclusion criteria were having hemophilia based on a medical diagnosis and tests available 
in medical records, living in Zahedan, studying at senior elementary school or junior high school, being able to cooperate and implement the program, not dealing with any other diseases except hemophilia based on a physician's opinion and medical records (some patient with asthma, kidney failure, etc. exclude from study) and also, not taking part in any other psychological interventions. To collect data, the following measurement tools were used.

\section{Sarason test anxiety scale}

This scale was designed by Sarason in 1957 and includes 37 yes/no items, which should be answered in 10 to 15 minutes. The higher the score of a subject, the more he/she suffers from test anxiety. When scoring the items, no answers to questions $3,15,26,27,29$, and 33 are scored 1. This is while yes answers to other questions are scored 1. After summing up the scores, a subjects' score on test anxiety is obtained. Higher scores indicate higher levels of test anxiety. Subjects are placed into the following three categories based on their scores: Mild test anxiety (12 and lower scores), moderate test anxiety (13 to 20), severe test anxiety ( 21 and higher scores). The reliability and validity of this scale were examined in several studies. Results of which demonstrated that its Cronbach's alpha coefficient, internal consistency, and criterion validity were $0.88,0.95$, and 0.72 respectively that were all acceptable.

\section{Positive psychotherapy sessions}

After obtaining a license from the Education Department, presenting it to the Health Deputy of Zahedan
University of Medical Sciences, and referring to Zahedan Hemophilia Society, the society was regarded as the research environment. Afterward, through explaining the main objectives and importance of conducting this study and assuring the subjects that their information would remain confidential, informed consents were obtained from all the subjects who were willing to take part in the current study. The subjects were assured of both confidentiality and anonymity. The positive psychotherapy, as an independent variable, was only carried out on the experimental group and its effectiveness in posttest and follow-up scores was examined. The experimental group took part in eight positive psychotherapy sessions within 4 weeks (two 120-minute sessions per week), however, the control group did not receive any training. After completing the intervention, both groups completed the questionnaire at the same time. A two-month follow-up was also conducted after the end of the last session on both groups. After completing this study, the control group received the same positive psychotherapy together with a training package (details of therapy sessions presents in Table 2).

Table 1. Age statistics in experimental and control groups.

\begin{tabular}{lccc}
\hline Group & Number & Mean & S.D \\
\hline Experimental & 29 & 14.28 & 2.70 \\
\hline Control & 28 & 13.08 & 2.59 \\
\hline
\end{tabular}

Table 2. Summary of the structure and content of therapy sessions (based on the treatment protocol proposed by Seligman et al., 2005).

\begin{tabular}{|c|c|c|c|}
\hline Session & Topic & Content and Activities & Homework assignment \\
\hline First & Creating initial communications & $\begin{array}{l}\text { Creating initial communications, becoming } \\
\text { familiar with the subjects, and stating the } \\
\text { objectives of holding these sessions }\end{array}$ & $\begin{array}{l}\text { Writing down all strengths the subjects can find } \\
\text { out in themselves }\end{array}$ \\
\hline Second & Identifying personal capabilities & $\begin{array}{l}\text { Examining and discussing the method of } \\
\text { applying the subjects'strengths in their } \\
\text { daily lives }\end{array}$ & $\begin{array}{l}\text { Writing down their strengths from others' } \\
\text { viewpoints }\end{array}$ \\
\hline Third & $\begin{array}{l}\text { Creating positive emotions and } \\
\text { mentioning blessings }\end{array}$ & $\begin{array}{l}\text { Discussing the gratitude for providing } \\
\text { supplementary activities }\end{array}$ & Writing thank you letters to friends \\
\hline Fourth & Training how to be positive & $\begin{array}{l}\text { Talking about the experience of enjoying } \\
\text { the present through focusing on the present }\end{array}$ & $\begin{array}{l}\text { Enjoying the present and recording sweet } \\
\text { experiences the subjects gained in the last week }\end{array}$ \\
\hline Fifth & Positive self-talk & $\begin{array}{l}\text { Discussing constructive and active } \\
\text { responsiveness and engagement with people }\end{array}$ & $\begin{array}{l}\text { Teaching the responsiveness style and improving } \\
\text { relationships with others }\end{array}$ \\
\hline Sixth & Increasing hope and setting goals & $\begin{array}{l}\text { Talking about personality traits and values } \\
\text { which the subjects wish to have in the future }\end{array}$ & $\begin{array}{l}\text { Adding abilities the subjects achieved during the } \\
\text { last week to their lists }\end{array}$ \\
\hline Seventh & Using capabilities in a new way & $\begin{array}{l}\text { Talking about positive abilities and the } \\
\text { methods of developing such abilities }\end{array}$ & $\begin{array}{l}\text { Collecting positive features that have been } \\
\text { achieved so far and increasing hope }\end{array}$ \\
\hline Eighth & Summing up the expression of emotions & $\begin{array}{l}\text { Talking about positive thinking and practicing } \\
\text { the acquired skills }\end{array}$ & $\begin{array}{l}\text { Increasing positive emotions, determining the } \\
\text { time of conducting a posttest, and acknowledging } \\
\text { the subjects' participation }\end{array}$ \\
\hline
\end{tabular}




\section{Results}

$79.3 \%$ of the subjects in the experimental group were in the age range of 10 to 15 years and $20.7 \%$ of them were in the age range of 16 to 20 years. This is while $82.1 \%$ of the subjects in the control group were in the age range of 10 to 15 years and $17.8 \%$ of them were in the age range of 16 to 20 years. $58.6 \%$ of the subjects in the experimental group and $57.1 \%$ of the subjects in the control group were male. Moreover, $58.6 \%$ of the subjects were studying in senior elementary school and $41.4 \%$ of them were studying in junior high school. However, $64.3 \%$ of the subjects in the control group were studying in senior elementary school and $35.7 \%$ of them were studying in junior high school. Respectively, $37.9 \%$ and $39.3 \%$ of the subjects in the experimental and control groups were the first children. Table 3 presents means and standard deviations of scores on test anxiety obtained by the experimental and control groups in the pretest, posttest, and follow-up.

As presented in Table 3, before carrying out the intervention, the mean score of the experimental group on test anxiety was 22.89 . However, this score decreased to 17.65 after the intervention. This decrease in the scores on test anxiety was quite clear in the follow-up.

Before performing repeated measures ANOVA, initially, its assumptions were examined using Box's test. Results of the Box's test $(\mathrm{F}=1.490, \mathrm{P}=0.177)$ indicated that covariance matrices of the independent variable were equal. Results of the Levene's test in the pretest ( $\mathrm{F}(1$, $55)=0.006, \mathrm{P}=0.937)$, posttest $(\mathrm{F}(1,55)=0.003, \mathrm{P}=0.956)$ and follow-up $(\mathrm{F}(1,55)=0.842, \mathrm{P}=0.040)$ were not significant. This finding demonstrated that the two groups had equal variances. In the next step, another assumption (the assumption of sphericity) was assessed by Mauchly's test. Results of this test were not significant $(\mathrm{P}<0.05)$. This means that the assumption of sphericity was met. Results of examining the intergroup effects of test anxiety are presented in Table 4. The results of the repeated measures ANOVA indicated that the time of measurement had a significant effect on test anxiety. In other words, the decrease in the test anxiety scores in the posttest and follow-up $(\mathrm{F}=543.44, \mathrm{P}=0.05)$ with an effect size of 0.908 and the time and group interaction for this variable $(\mathrm{F}=136.904$, $\mathrm{P}=0.05$ ) with an effect size of 0.914 were significant. Additionally, the difference in the test anxiety scores obtained by the experimental and control groups with an effect size of 0.172 was significant.

The results presented in Table 5 demonstrated that the difference between the mean scores of test anxiety in the pretest and posttest was significant. On the other hand, the difference between the mean scores of test anxiety in the follow-up and pretest was significant. However, the difference between the mean scores of test anxiety in follow-up and posttest was not significant. This result indicated the stability of the effect of positive psychotherapy on test anxiety among the subjects assigned to the experimental group in the follow-up.

Table 3. The means and standard deviations of scores on test anxiety obtained by both groups.

\begin{tabular}{llccc}
\hline Group & & Number & Mean & SD \\
\hline Experimental & Pretest & 29 & 22.89 & 4.108 \\
& Posttest & 29 & 17.58 & 3.914 \\
& Two-month follow-up & 29 & 17.65 & 3.930 \\
\hline \multirow{2}{*}{ ontrol } & Pretest & 28 & 22.96 & 4.290 \\
& Posttest & 28 & 23.14 & 4.187 \\
& Two-month follow-up & 28 & 22.96 & 4.095 \\
\hline
\end{tabular}

Table 4. The results of the repeated measures ANOVA conducted to examine the intragroup and intergroup effects of test anxiety.

\begin{tabular}{llcccccc}
\hline Effect & & Sum of squares & Df & Mean of squares & F & P-value & Eta-squared \\
\hline Intragroup & Group & 567.647 & 1 & 567.647 & 11.429 & 0.05 & 0.172 \\
\hline Intergroup & $\begin{array}{l}\text { Time of measurement (pretest, } \\
\text { posttest, and follow-up) }\end{array}$ & 255.562 & 2 & 127.781 & 543.44 & 0.05 & 0.908 \\
& Time and group interaction & 273.808 & 2 & 136.904 & 582.243 & 0.05 & 0.914 \\
\hline
\end{tabular}

Table 5. The results of Bonferroni's post hoc test conducted for test anxiety.

\begin{tabular}{lcccccc}
\hline Dependent & \multicolumn{2}{c}{ Pretest-Posttest } & \multicolumn{2}{c}{ Pretest-Follow-up } & \multicolumn{2}{c}{ Posttest-Follow-up } \\
\hline variable & Mean difference & Standard error & Mean difference & Standard error & Mean difference & Standard error \\
\hline Test anxiety & 2.566 & 0.092 & 2.621 & 0.097 & 0.055 & 0.084 \\
\hline
\end{tabular}




\section{Discussion}

This study was conducted with the aim of evaluating the effectiveness of positive psychotherapy in reducing test anxiety among the senior elementary and junior high school students with hemophilia who had medical records in Zahedan Hemophilia Society. The results of the present study showed that positive psychotherapy was effective in reducing test anxiety among the students with hemophilia and its effects remained stable till the follow-up. This finding is consistent with results of several other studies which indicated the effectiveness of positive psychotherapy in decreasing test anxiety (Bagana et al., 2011). To explain the effectiveness of this therapy in reducing test anxiety among the students with hemophilia, it can be mentioned that this therapy, plays a key role in the mentioned changes. The obtained results are in line with the main assumption of a positive psychotherapy approach. In this approach, through creating positive emotions and enhancing a person's capabilities, his/her emotional and mental issues can be reduced effectively (Peters, Meevissen, \& Hanssen, 2013; Sergeant \& Mongrain, 2014). Seligman believes optimism can be learned (Seligman \& Csikszentmihalyi, 2014; Seligman et al., 2005). Considering this assumption in this study we attempted to teach positive thinking techniques such as identification of thoughts, attention to emotions, discover abilities, looking the event from different aspects and providing a suitable model for explaining and analyzing events. In positive psychotherapy patients are encouraged to learn, recognize positive and good experiences and also recognize their role in increasing self-respect and self-esteem. Moreover, be able to recognize the positive aspects of others. Indeed, due to creating positive emotions, thoughts and behaviors, positive psychotherapy leads to decrease test anxiety and increase in happiness and psychological well-being (Lyubomirsky \& Layous, 2013). Additionally, positive psychological interventions are effective in enhancing mental and physical well-being and reducing interpersonal and mental issues (SchotanusDijkstra, Drossaert, Pieterse, Walburg, \& Bohlmeijer, 2015; Schotanus-Dijkstra et al., 2016). The essential element of positive psychotherapy is training individuals to pay more attention to positive emotions and the methods of creating positive resources. In other words, increasing positive emotions aids people to apply more adaptive responses when dealing with difficult situations (Zeykani \& Nikmanesh, 2017). The other important advantage of applying this psychotherapy is that positive psychotherapy exercises are developed in such a way that a person himself/herself can take advantage of them without the need for a psychologist. This confirms the effectiveness of this psychotherapy in the follow-up (Layous, Chancellor, Lyubomirsky, Wang, \& Doraiswamy, 2011). However, the knowledge about the specific aspects of the chronic disease is still strict but researches show that chronic patients have a high level of anxiety that affected psychological aspects of their life. Moreover, we must not forget that the perception of life is a mental state and may differ from one person to another depending on individuals' experiences during their life. On the other hand, adolescence is associated with physical and cognitive changes and thoughts are of particular importance. By controlling the mind and attracting it to the positive points of events, it is possible to improve patients' performance. If patients can recognize and control their thoughts, they will have a better psychological status and experience a better life. In other words, the person's thinking of how he or she responds to life is important. Positive people believe they can change life and get the ability to succeed in succeeding times and vice versa. Furthermore, researchers have evaluated anxiety disorder as the most common psychological disorder. Prospective studies have shown that disorders such as anxiety (especially in girls) may occur in childhood likely increase the risk of developing psychiatric illnesses in adulthood (Zarrella, Russolillo, Caviglia, $\&$ Perrella, 2017). There is also a significant correlation between childhood and adolescent anxiety disorder and tend to reform to depressive disorders and vice versa. Also, long-term studies with big sample size show that anxiety disorders in childhood will increase in adulthood by up to three times and can become chronic and permanent injuries and also likely lead to drug abuse and behavioral disorders and affect some aspects of social, occupational, relationship and so on (Zarrella et al., 2017). Among limitations of the present study, lack of research background and the fact that no studies were conducted to examine the effectiveness of positive psychotherapy in reducing test anxiety among student patients can be mentioned. It seems that this issue was first investigated in this study. Although this indicates that the current study was innovative and creative, carrying out this study was accompanied by certain issues. Accordingly, it is recommended that further studies be conducted to confirm the effectiveness of this therapy. Moreover, conducting other studies aimed at controlling the existence or absence of the effect of any possible bias on the results is highly suggested. On the other hand, some confounding variables, such as the subjects' types of personality, life history, and family life status, are among important factors which were not controlled in this study. This is why should be cautious when generalizing and interpreting the obtained results.

\section{Conclusions}

Through providing positive psychotherapy, nurses working in hospitals and school counselors can aid student patients to improve their mental health and increase their learning activities. In addition, by creating good interactions between these two groups and providing positive feedback to their success, these patients can be aided to reduce their test anxiety. 


\section{References}

Bagana, E., Raciu, A., \& Lupu, L. (2011). Self esteem, optimism and exams' anxiety among high school students. ProcediaSocial and Behavioral Sciences, 30, 1331-1338.

Bolier, L., Haverman, M., Westerhof, G. J., Riper, H., Smit, F., \& Bohlmeijer, E. (2013). Positive psychology interventions: a meta-analysis of randomized controlled studies. BMC Public Health, 13, 119.

Caldwell, H. S., Leveque, K. L., \& Lane, D. (1974). Group psychotherapy in the management of hemophilia. Psychological reports, 35, 339-342.

De Moor, J. S., De Moor, C. A., Basen-Engquist, K., Kudelka, A., Bevers, M. W., \& Cohen, L. (2006). Optimism, distress, health-related quality of life, and change in cancer antigen 125 among patients with ovarian cancer undergoing chemotherapy. Psychosomatic Medicine, 68, 555-562.

DeKoven, M., Karkare, S., Kelley, L., Cooper, D., Pham, H., Powers, J., ...Wisniewski, T. (2014). Understanding the experience of caring for children with haemophilia: cross-sectional study of caregivers in the United States. Haemophilia, 20, 541-549.

Donovan, C. L., \& Spence, S. H. (2000). Prevention of childhood anxiety disorders. Clinical Psychology Review, 20, 509-531.

Iannazzo, S., Cortesi, P. A., Crea, R., Steinitz, K., Mantovani, L. G., \& Gringeri, A. (2017). Cost-effectiveness analysis of pharmacokinetic-driven prophylaxis vs. standard prophylaxis in patients with severe haemophilia A. Blood Coagulation \& Fibrinolysis, 28, 425-430.

Jafari, S., Mohtashami, J., Alaee Karahroudi, F., Mansouri, S., \& Rassouli, M. (2016). Perceived Social Support and Its Correlated Factors in Adolescents with Chronic Disease. Journal of Hayat, 22, 65-78.

Ji, J. L., Holmes, E. A., \& Blackwell, S. E. (2017). Seeing light at the end of the tunnel: Positive prospective mental imagery and optimism in depression. Psychiatry research, 247, 155-162.

Kendall, P. C., Hudson, J. L., Gosch, E., Flannery-Schroeder, E., \& Suveg, C. (2008). Cognitive-behavioral therapy for anxiety disordered youth: a randomized clinical trial evaluating child and family modalities. Journal of Consulting and Clinical Psychology, 76, 282.

Khodabakhsh, R., Khosravi, Z., \& Zarrinpour, N. (2015). Effect of positive psychotherapy in depression symptoms and character strengths in cancer affected patients. Positive Psychology Research, 1, 35-49.

Layous, K., Chancellor, J., Lyubomirsky, S., Wang, L., \& Doraiswamy, P. M. (2011). Delivering happiness: Translating positive psychology intervention research for treating major and minor depressive disorders. The Journal of Alternative and Complementary Medicine, 17, 675-683.

Linton, S. J., \& Shaw, W. S. (2011). Impact of psychological factors in the experience of pain. Physical Therapy, 91, 700-711.

Lyubomirsky, S., \& Layous, K. (2013). How do simple positive activities increase well-being? Current directions in psychological science, 22, 57-62.

Mento, C., Piraino, B., Rizzo, A., Vento, R., Rigoli, L., Moschella, E., ...Settineri, S. (2015). Affective control and life satisfaction in thalassemics. International Journal of Psychological Research, 8, 90-97.

Peters, M. L., Meevissen, Y., \& Hanssen, M. M. (2013). Specificity of the best possible self intervention for increasing op- timism: Comparison with a gratitude intervention. Terapia Psicológica.

Rambod, M., Forsyth, K., Sharif, F., \& Khair, K. (2016). Assessment and management of pain in children and adolescents with bleeding disorders: a cross-sectional study from three haemophilia centres. Haemophilia, 22, 65-71.

Sarmad, Z., Bazargan, A., \& Hejazi, E. (2002). Methods of research in behavioral sciences. 3rd ed. Tehran: Publishing Aware.

Schotanus-Dijkstra, M., Drossaert, C. H., Pieterse, M. E., Walburg, J. A., \& Bohlmeijer, E. T. (2015). Efficacy of a multicomponent positive psychology self-help intervention: study protocol of a randomized controlled trial. JMIR Research Protocols, 4, e:105.

Schotanus-Dijkstra, M., Pieterse, M. E., Drossaert, C. H., Westerhof, G. J., De Graaf, R., Ten Have, M., ... Bohlmeijer, E. T. (2016). What factors are associated with flourishing? Results from a large representative national sample. Journal of Happiness Studies, 17, 1351-1370.

Seligman, M. E., \& Csikszentmihalyi, M. (2014). Positive psychology: An introduction. In Flow and the foundations of positive psychology (pp. 279-298). New York, NY: Springer.

Seligman, M. E., Steen, T. A., Park, N., \& Peterson, C. (2005). Positive psychology progress: empirical validation of interventions. American Psychologist, 6, 410.

Sergeant, S., \& Mongrain, M. (2014). An online optimism intervention reduces depression in pessimistic individuals. Journal of Consulting and Clinical Psychology, 82, 263.

Shoshani, A., Mifano, K., \& Czamanski-Cohen, J. (2016). The effects of the make a wish intervention on psychiatric symptoms and health-related quality of life of children with cancer: a randomised controlled trial. Quality of Life Research, 25, 1209-1218.

Sidonio, R., Holot, N., \& Cooper, D. L. (2017). Evaluating the psychosocial impact of hemophilia B: The Bridging Hemophilia B Experiences, Results and Opportunities into Solutions (B-HERO-S) study. European Journal of Haematology, 98, 3-4.

Stewart, M. E., Watson, R., Clark, A., Ebmeier, K. P., \& Deary, I. J. (2010). A hierarchy of happiness? Mokken scaling analysis of the Oxford Happiness Inventory. Personality and Individual Differences, 48, 845-848.

Strauss, C. C., Last, C. G., Hersen, M., \& Kazdin, A. E. (1988). Association between anxiety and depression in children and adolescents with anxiety disorders. Journal of Abnormal Child Psychology, 16, 57-68.

Takahashi, A., Flanigan, M. E., McEwen, B. S., \& Russo, S. J. (2018). Aggression, social stress and the immune system in humans and animal models. Frontiers in Behavioral Neuroscience, $12,56$.

Torres-Ortuño, A., Cid-Sabatel, R., Barbero, J., \& García-Dasí, M. (2017). Life experience of the adult and ageing patient with haemophilia. Practical aspects for psychological support. Vox Sanguinis.

Vanneste, Y., van de Loo, M., Feron, F., Rots-de Vries, C., \& van de Goor, I. (2016). Attitudes towards addressing medical absenteeism of students: a qualitative study among principals and special education needs coordinators in Dutch secondary schools. PloS One, 11, e0148427.

Wood, J. J., Drahota, A., Sze, K., Har, K., Chiu, A., \& Langer, D. A. (2009). Cognitive behavioral therapy for anxiety in children with autism spectrum disorders: A randomized, controlled trial. Journal of Child Psychology and Psychiatry, 50, 224-234. 
Zarrella, I., Russolillo, L. A., Caviglia, G., \& Perrella, R. (2017). Continuity and discontinuity between psychopathology of childhood and adulthood: a review on retrospective and prospective studies. Research in Psychotherapy: Psychopathology, Process and Outcome, 20, 101-109.

Zeykani, M., \& Nikmanesh, Z. (2017). The effect of positive psychotherapy on perceived competence and quality of life among children with thalassemia. Jundishapur Journal of Chronic Disease Care [In Press].

Zunhammer, M., Eichhammer, P., \& Busch, V. (2014). Sleep quality during exam stress: The role of alcohol, caffeine and nicotine. PloS One, 9, e109490. 